\title{
MEASUREMENT OF NARCISSISM: FROM CLASSICAL APPLICATIONS TO MODERN APPROACHES
}

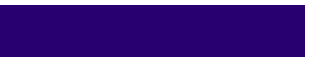 \\ RADOSŁAW ROGOZA * \\ MAGDALENA ŻEMOJTEL-PIOTROWSKA \\ Cardinal Stefan Wyszyński University in Warsaw, Poland \\ W. KEITH CAMPBELL \\ University of Georgia, United States of America
}

\begin{abstract}
Different conceptions of narcissism exist within the literature such as grandiose, vulnerable, pathological, collective, and communal, each of

which can be measured using self-report measures. Within the current paper, we review and discuss most of the existing measures of these different trait (i.e., non-clinical) narcissism constructs. This includes an examination of their underlying theoretical foundations and an evaluation of the scale construction process. We start our review from the one-dimensional measures of grandiose and vulnerable narcissism such as the Narcissistic Personality Inventory, the Hypersensitive Narcissism Scale, the Dark Triad Dirty Dozen, the Short Dark Triad, the Narcissistic Grandiosity Scale, the Warcissistic Vulnerability Scale, and the Single Item Narcissism Scale. Then, we introduce the multidimensional measures to study narcissism such as the Narcissistic Admiration and Rivalry Questionnaire, the Five Factor Narcissism Inventory, and the Pathological Narcissism Inventory. The review concludes by presenting measures of understudied narcissistic constructs such as the Communal Narcissism Inventory and the Collective Narcissism Scale. In general, using one-dimensional scales might provide important insights into the general underpinnings of narcissistic personality, however assessment via multi-dimensional tools better reflects its complex nature.
\end{abstract}

NARCISSISM

GRANDIOSITY

VULNERABILITY

COMMUNAL NARCISSISM

COLLECTIVE NARCISSISM MEASUREMENT

号

28 INTRODUCTIONA

29 SINGLE PHENOTYPE MEASURES OF NARCISSISM

29 Narcissistic Personality Inventory (NPI)

30 Hypersensitive Narcissism Scale (HSNS)

31 Narcissism in the Dark Triad

32 Discussion of narcissism in the Dark Triad

32 Measuring (grandiose?) narcissism: single-item scale (SINS)

33 Adjective measures of narcissism - theoretical foundations

33 Narcissistic Grandiosity Scale

33 Narcissistic Vulnerability Scale

34 Discussion of the adjective measures of narcissism

35 MULTIDIMENSIONAL MEASURES OF NARCISSISM

35 Pathological Narcissism Inventory (PNI)

36 Five Factor Narcissism Inventory (FFNI)

36 Narcissistic Admiration and Rivalry Questionnaire (NARQ)

37 Discussion of the multidimensional measures of narcissism

39 BEYOND NARCISSISM SPECTRUM MODEL

39 Communal Narcissism Inventory (CNI)

41 Collective narcissism Scale (CNS)

42 SUMMARY

44 CONCLUSIONS

44 REFERENCES 
Summary of the narcissism measures described in this paper

\begin{tabular}{lll}
\hline Abbreviation & \multicolumn{1}{c}{ Full name } & Reference \\
\hline NPI & Narcissistic Personality Inventory & Raskin \& Hall (1979) \\
\hline HSNS & Hypersensitive Narcissism Scale & Hendin \& Cheek (1997) \\
\hline DTDD & Dark Triad Dirty Dozen & Jonason \& Webster (2012) \\
\hline SD3 & Short Dark Triad & Jones \& Paulhus (2014) \\
\hline SINS & Single Item Narcissism Scale & Konrath, Maier, \& Bushman (2014) \\
\hline NGS & Narcissistic Grandiosity Scale & Crowe, Carter, Campbell, \& Miller (2016) \\
\hline NVS & Narcissistic Vulnerability Scale & Rosenthal, Hooley, Montoya, van der Linden, \& Steshenko (2019) \\
\hline PNI & Pathological Narcissism Inventory & Pincus, Ansell, Pimentel, Cain, Wright, \& Levy (2009) \\
\hline FFNI & Five Factor Narcissism Inventory & Glover, Miller, Lynam, Crego, \& Widiger (2012) \\
\hline NARQ & Narcissistic Admiration and Rivalry Questionnaire & Back, Küfner, Dufner, Gerlach, Rauthmann, \& Denissen (2013)
\end{tabular}

KRIZAN AND HERLACHE:

Definition of narcissism

\section{INTRODUCTION}

N arcissism can be defined as entitled self-importance (Krizan, 2018) that itself can be expressed as two phenotypes: grandiosity (regarding self-aggrandizement and self-absorption; Morf \& Rhodewalt, 2001) and vulnerability (reflecting feelings of inadequacy, incompetence and negative affect; Miller et al., 2011). These two-factor models of narcissism (i.e., grandiose and vulnerable) can be further described using three dimensions. At the core of both grandiose and vulnerable narcissism is entitled self-importance (Narcissism Spectrum Model; NSM; Krizan \& Herlache, 2018), or antagonism/disagreeablenss (Trifurcated Model of Narcissism; Campbell \& Miller, 2017; Miller, Lynam, Hyatt, \& Campbell, 2017).

The current paper aims to present and discuss contemporary measures of non-clinical narcissism, reflecting up-to-date findings in the field. For this reason, we present information about the process of construction and validation and discuss the convergence and divergence between single- and multidimensional narcissism scales. Moreover, as narcissism is a complex construct, we interpret how most of the existing measures of non-clinical narcissism measures refers to its dimensions. 


\section{SINGLE PHENOTYPE MEASURES OF NARCISSISM}

\section{NARCISSISTIC PERSONALITY INVENTORY (NPI; RASKIN \& HALL, 1979)}

Theoretical foundations. The NPI was developed as a measure of narcissism during the late 1970's (Raskin and Hall; 1979). The initial item pool of the NPI was created to capture the eight diagnostic criteria for narcissistic personality disorder (NPD) in the DSM-III: grandiose sense of self-importance, preoccupation with fantasies, exhibitionism, cool indifference or marked feelings in response to criticism, entitlement, interpersonal exploitativeness, fluctuating relationships, and a lack of empathy (APA, 1980). Because the NPD diagnostic criteria (as opposed to the clinical description) are saturated with grandiosity, the NPI emerged as a measure of grandiose narcissism rather than capturing both grandiosity and vulnerability. The initial pool of items comprised 223 pairs of forced-choice sentences covering all of the DSM-III NPD criteria. Namely, each pair comprised one narcissistic and one non-narcissistic response and the respondent was forced to choose only one of them.

Construction. First, Raskin and Hall (1979) administered this measure to a sample of $N$ $=71$ students. Second, this sample was divided into two subsamples scoring either low or high on the overall score, each with $n=20$ students. Third, each item was compared between the high and low subsamples, and if the difference was significant the item was retained, if not - the item was removed. This procedure resulted in the generation of 80 pairs of items, which formed two parallel and equivalent forms of the questionnaire, (i.e., NPI A and NPI B; Raskin \& Hall, 1979). During follow-up studies, additional items were removed in order to maximize reliability and item-total correlations, which resulted in a 54-item measure of narcissism understood as a unidimensional construct (Raskin \& Hall, 1979; Raskin \& Hall, 1981; Raskin \& Terry, 1988).

Further development - towards multidimensionality. The generated pool of 54-items was independently reduced using a factor-analytic approach by Emmons $(1984 ; 1987)$ and Raskin and Terry (1988) to 37- and 40-item multidimensional measures, respectively. Emmons (1984; 1987) argued that there are four factors labeled as: 1) Exploitativeness/Entitlement, Leadership/Authority, Superiority/Arrogance, and Self-absorption/Self-admiration while Raskin and Terry (1988) advocated the existence of seven distinct factors labeled: 1) Authority, 2) Self-Sufficiency, 3) Superiority, 4) Exhibitionism, 5) Exploitativeness, 6) Vanity, and 7) Entitlement. The construction of the 40-item version of the NPI (Raskin \& Terry, 1988) was the last classical reduction of the items and it is still, 30 years later, frequently used in research on narcissism.

Modern versions of the NPI. Existing research has demonstrated that the factorial structure of the NPI is unstable (e.g., Barelds \& Dijkstra, 2010; Kansi, 2003; Svindseth et al., 2009); however, some of the existing models are describing the underlying structure more precisely than the others. Ames, Rose, and Anderson (2006) proposed that the NPI can be shortened just to 16-items while maintaining good overall reliability and covering the breadth of the construct. Although this goal is plausible, the factorial validity of the NPI-16 has yet to be clearly established. Ackerman et al. (2011) synthetized previous research, analyzed the full version of the NPI, and claimed that the three-factor model is the best to describe the NPI's structure. The three factors were assigned to the normal (Leadership/Authority) or antagonistic aspects narcissism (with Grandiose Exhibitionism as an intra- and Entitlement/Exploitativeness as an interpersonal cluster). This model was tested in Gentile et al. (2013) who proposed a brief 13-item measure. Although it yielded good model fit and the structure was partially replicated in different cultures (Żemojtel-Piotrowska et al., 2018), it also inherited some of the weaknesses of the original NPI. For instance, three out of five Grandiose Exhibitionism items with highest factor loadings actually refer to body

CLASSICAL MEASUREMENT OF GRANDIOSE NARCISSISM:

Narcissistic Personality Inventory 
satisfaction and exhibitionistic tendencies (e.g., I like to show off my body), suggesting that vanity may be overrepresented. Finally, Ackerman et al. (2016) tested the effects of the response format on the underlying structure of the NPI. The results suggested that using a single stimulus response format changes the underlying structure as five meaningful factors could be differentiated. More recent research, however, has found that using a forced-choice vs. a Likert-type scale on the NPI does relatively little to change the NPI's validity (Miller, et al., 2018).

Discussion of the development of the NPI. The original 223 dyadic items were created to cover all of the DSM-III (APA, 1980) NPD criteria, which itself can be seen as a satisfactory theoretical foundation covering all of the important aspects of narcissism. However, as narcissism was initially conceptualized as a unidimensional construct without any particular facets, the whole process of data reduction did not attempt to evenly retain items referring to specific NPD criteria. In fact, some of these criteria refer to aspects of narcissism which have some social potential (like requiring constant attention and admiration), whilst others refer to vulnerable aspects (like marked feelings in response to criticism and indifference of others or defeat). In the initial step, where 143 dyadic items were removed, Raskin and Hall (1979) compared 40 individuals who scored low (20) vs high (20) on narcissism from an initial sample of 71 students. As the antagonistic aspects of narcissism are less likely to occur than the agentic aspects (Wetzel et al., 2016), many of the items from the initial item pool referring to the antagonistic character of narcissism were presumably removed during the scale reduction process. Moreover, the scales capturing socially malevolent aspects tend to have lower reliability (Ackerman et al., 2011). However, Raskin and Hall (1979) also removed such items during the development of the NPI in order to maximize reliability, which resulted in an uneven coverage of antagonistic and agentic aspects by the NPI. Although modern versions of the NPI have been developed (Ames et al., 2006; Gentile et al., 2013) and the classical version has been tested under different response formats (Ackerman et al., 2016) all of them inherited the strengths and the weaknesses of the original NPI. Thus, although the NPI provides useful information about grandiose narcissism, it is not as detailed and precise as the multidimensional narcissism measures.

\section{HYPERSENSITIVE NARCISSISM SCALE (HSNS; HENDIN \& CHEEK, 1997)}

Theoretical foundations. The HSNS was developed as a measure of vulnerable narcissism in response to the seminal study of Wink (1991) who noted that there is a lack of correlation between the NPI and the NPD scales, demonstrating that narcissism is not only about grandiosity, but that it also includes a distinct phenotype known as vulnerability-sensitivity. This face of narcissism was shown to have significantly lower well-being, poorer personal adjustment, and to be more emotional, worrying, anxious, and tense (Wink, 1991). Hendin and Cheek (1997) followed this theoretical distinction and compared it to Murray's (1938) distinction between overt and covert narcissism, which theoretically might be compared to the dimensions distinguished by Wink (1991) as overt narcissism is characterized by aggressiveness, self-aggrandizing, exploitativeness, and delusions of grandeur, whereas covert narcissism is characterized by a proneness to feel neglected or belittled, anxiousness, hypersensitiveness, and delusions of persecution.

Construction. The HSNS was developed on the basis of the 20-item Murray's Narcism Scale (1938). It was administered to samples with total $N=260$ alongside the Narcissistic Personality Disorder Scale (Ashby, Lee, \& Duke, 1979), the Serkwonek (1975) Narcissism-Hypersensitivity Scale, the NPI (Raskin \& Terry, 1988), and the Big Five Personality Inventory (John, Donahue, \& Kentle, 1991). Two of these scales (i.e., Ashby et al., 1979 and Serkwonek, 1975) were combined to produce the composite MMPI-based 
(as demonstrated in Wink, 1991) measure of covert narcissism. Each item from Murray's (1938) scale was correlated with the MMPI composite and the NPI and items which correlated positively with the MMPI composite score were selected to form the HSNS (Hendin \& Cheek, 1997). The remaining ten items, which did not correlate at all or correlated with NPI - were removed from the measure. The HSNS demonstrated a clearly different pattern of relations with the Big Five traits than the NPI as it was positively correlated with neuroticism (NPI, n.s.), negatively with extraversion, openness to experience (NPI positively) and agreeableness (NPI, n.s.).

Discussion of the development of the HSNS. Whereas a massive amount of research was devoted to analyzing the NPI structure in different cultural contexts and confirmed that the NPI is not an unidimensional measure (Corry, Merritt, Mrug, \& Pamp, 2008), there is a lack of similar studies devoted to the HSNS. Arble (2006) suggested that the HSNS comprises three factors, while Fossati et al. (2009) claimed that the HSNS comprises not one nor three, but two-factors related to oversensitivity to judgement and to egocentrism. Because this underlying factorial structure was not further replicated nor challenged and neither of the existing studies used more stringent statistical techniques (e.g., confirmatory factor analysis), the underlying structure of the HSNS remains unclear.

\section{NARCISSISM IN THE DARK TRIAD}

Theoretical foundations. Grandiose narcissism is considered to be a part of a broader personality construct labeled as the Dark Triad of personality, which comprises three socially malevolent traits: narcissism, psychopathy, and Machiavellianism (Paulhus \& Williams, 2002). Although it is frequently assessed using independent measures, two brief measures were developed to study all of the Dark Triad traits simultaneously. The theoretical foundations of narcissism within the Dark Triad are based on the conceptualization of grandiose narcissism, and especially the NPI.

Dark Triad Dirty Dozen (DTDD; Jonason \& Webster, 2012). The scale was developed in response to the growing research interest in the construct of Dark Triad, of which measurement was inefficient (i.e., standard measures required 91 items; Jonason \& Webster, 2012). Therefore, authors originally developed 22 items tapping into central features of all Dark Triad traits (11 for narcissism; 6 for psychopathy, and 5 for Machiavellianism), which were inspired by the original Dark Triad measures (and in the case of narcissism- the NPI; Raskin \& Terry, 1988). All of the generated items were the subject of a principal component analysis in two independent studies, and the four items with highest factor loading on the first rotated factor were retained in the final version. The confirmatory factor analysis verified that the distinguished three-factor structure was well-fitted to the data. In regard to the correlates of narcissism, the results provided by Jonason and Webster (2012) demonstrated that it is only moderately associated with the NPI total score (Raskin \& Terry, 1988), weakly related to basic personality traits ( $\mathrm{rs}<.20)$ when a standard measure, the Big Five Inventory, was used (Benet-Martinez \& John, 1998), and weakly ( $\mathrm{r}=-.13$ ) but negatively to self-esteem (as measured by Rosenberg Self-Esteem Scale; Rosenberg, 1965), which challenges the criterion validity of narcissism as measured by the DTDD.

Short Dark Triad (SD3; Jones \& Paulhus, 2014). The SD3 was developed as an alternative to the DTDD for capturing the Dark Triad traits (Jones \& Paulhus, 2014). The initial item pool, created from the Jones and Paulhus (2011) review of the literature covering key aspects (for narcissism: leadership, exhibitionism, grandiosity, and entitlement) of each Dark Triad trait, included 41 items. The items were reduced in a three-step procedure: first, eight items which failed to load on the first unrotated principal component were removed; second, five items which cross-loaded in exploratory factor analysis were removed; and third, items

DARK TRIAD:

Grandiose narcissism Machiavellianism, and psychopathy 
with lowest loadings in psychopathy were removed to keep the scales equal (nine items) in length. All of the key aspects of narcissism were maintained, however most of them (four) captured grandiosity, two items each covered entitlement and exhibitionism, and one item captured leadership. Among these, five items were heavily inspired by the NPI. The underlying structure was confirmed using exploratory structural equation modeling, in which a measurement model fitted the data well, however the strength of the factor loadings of four items were below .40. Narcissism as measured by the SD3 turned out to be highly convergent with the NPI (Raskin \& Terry, 1988), and had acceptable to good reliability estimates ranging from .68 to .80 .

\section{DISCUSSION OF NARCISSISM IN THE DARK TRIAD}

The research on the Dark Triad is flourishing (Furnham et al., 2013); however the inclusion of narcissism in the construct is not obvious. Existing research demonstrates that when the hierarchy of the Dark Triad is analyzed, narcissism is the very first to differentiate, suggesting its distinctiveness (Rogoza \& Cieciuch, 2018). The measures of the Dark Triad traits seem to benefit from this difference, as the order of items in SD3 is not random, but the narcissistic items split up Machiavellianism and psychopathy (Jones \& Paulhus, 2014), which might influence the obtained factorial structure (Podsakoff et al., 2012). Whilst Paulhus (2014) defines that a trait might be a part of "dark personality" if it is socially aversive, research demonstrates that narcissism frequently has socially desired correlates (Ackerman et al., 2011). It turns out that when narcissism, as measured by SD3, was compared with the NARC dimensions, it was more strongly related to the extraverted side of narcissism (i.e., admiration, while the antagonistic side of narcissism; rivalry was more strongly related to psychopathy and Machiavellianism; Rogoza, Kowalski, \& Schermer, 2019). Thus, including rivalry instead of or in addition to narcissism as conceptualized by the Dark Triad measures might shed new light on the antagonistic outcomes of narcissism and its utility in the construct of the Dark Triad.

\section{MEASURING (GRANDIOSE?) NARCISSISM: SINGLE-ITEM SCALE}

The Single Item Narcissism Scale (SINS, Konrath, Maier, \& Bushman, 2014) was designed to measure grandiose narcissism. It consists of one statement: "To what extent do you agree with this statement: I am a narcissist. (Note: The word 'narcissist' means egotistical, self-focused, and vain.)" with 11-point scale of answering (Konrath et al., 2014, p. 3). Authors validated the SINS in a series of 11 studies, indicating that the SINS is moderately correlated to general NPI scores. However, its relation to particular aspects vary from moderate $(r>.30$; Vanity, Exhibitionism, Exploitativeness) to rather weak $(.30>r>.20$, Superiority, Entitlement, Authority) to insignificant (Self-Sufficiency). Van den Linden \& Rosenthal (2016) examined the validity of the SINS, and concluded that despite its positive relationship with some grandiose narcissism measures (e.g., NPI and NGS) the SINS also captures some vulnerability, for example due to a slightly negative correlation with self-esteem. Despite the enthusiasm stemming from the these two validation studies with regards to the usefulness of the SINS as a screening tool, the complexity of the narcissism construct leads to a lack of clarity about the precise form measured by this scale and thus, future research is needed to better locate the SINS within the dimensions of the NSM (Krizan, 2018). 


\section{ADJECTIVE MEASURES OF NARCISSISM - THEORETICAL FOUNDATIONS}

A useful approach to measuring narcissism is offered by adjective measures. First, they are brief, and as a result they are less context dependent than classical items. Secondly, they are less biased and more intuitive than typical items describing attitudes and behaviors, as adjectives are typically used in self-perception. Finally, there is a substantial body of research, originating in the field of social cognition, showing that adjectives can be used in the assessment of morality/communion and agency. Namely, adjectives may be used to assess the fundamental dimensions of self and others perception (Wojciszke \& Abele, 2007), which is indicative of measurement invariance across different cultures and languages (Abele, Hauke, Peters, Louvet, Szymkow, \& Duan, 2016). Crowe and colleagues (Crowe, Carter, Campbell, \& Miller, 2016; Crowe et al., 2018) used adjective measures of narcissism to assess fluctuations in the levels of grandiose and vulnerable narcissism, as adjectives (e.g., "self-absorbed") allow for asking about one's current state, contrary to more general statements such as "I like having authority over others".

\section{NARCISSISTIC GRANDIOSITY SCALE (CROWE ET AL., 2016; ROSENTHAL ET AL., 2019)}

Construction. The NGS contains 16 items in adjective form, with a 7-point Likert-type scale. Adjectives are designed to measure grandiose narcissism as a homogenous phenomenon, therefore it is assumed to be unidimensional. The NGS was designed to capture the more narrowly defined narcissistic grandiosity, specifically, an internal feeling of superiority, without the interpersonal aspects of narcissism related to entitlement (Crowe et al., 2016). The scale was originally developed by Rosenthal and colleagues in 2007, but was published afterwards (Rosenthal et all., 2019). Despite this, the scale was used in numerous studies, which provided evidence for its good psychometric properties including its validity (Brown et al., 2009; Gentile et al., 2013; Miller et al., 2014). In particular, the NGS scores were positively correlated to the general scores of the NPI (Gentile, et al., 2013), as well as to agreeableness and extraversion (Miller, Price, \& Campbell, 2012). Interestingly, more extensive and systematic validation was done by Crowe et al. (2016). In addition to the validation of the scale, the authors aimed to create a shorter version of the NGS suitable for ecological momentary assessment (EMA) studies. The authors looked at the correlation patterns with established measures of personality as well as with narcissism and its nomological network, and especially entitlement, self-esteem, and interpersonal problems. On the basis of IRT analyses, Crowe et al. (2016) proposed and compared the 13-item and 6-item versions. The former was equally as good as its full version counterpart, while the 6-item version was recommended for repeated surveys, where the assessment of one's current state is especially important.

\section{NARCISSISTIC VULNERABILITY SCALE (CROWE ET AL., 2018)}

Construction. The NVS is an 11-item adjective-based assessment of vulnerable narcissism. This scale aims to assess vulnerable narcissism as a trait, and as a state. This last aim was particularly important, as the authors designed the NVS to capture fluctuations in vulnerable narcissism. The scale was constructed on the basis of 24 adjectives selected as relevant to vulnerability and then assessed by 17 experts in the field. Finally, 15 expert ratings were included in the analysis, and their evaluations were highly consistent. As a result, 12 items were selected for validation in three samples: two convenience samples, and one sample of psychology students. None of these samples included a clinical population. The final version 
consists of 11 items (one item was excluded due to redundancy). A one factor structure was successfully verified using both CFA and multilevel EFA, as the psychology student sample used a diary method. Namely, participants were interviewed using an EMA procedure with a week-long period, including a survey each morning, and six additional surveys spaced throughout the day on a blocked random schedule. During the survey, participants were asked about the "current situation" and therefore the procedure referred to their state and not to their general disposition (Crowe et al., 2018). Validation was based on correlations with an assortment of established personality and narcissism scales. The correlations were stronger for vulnerability measures than for scales measuring grandiosity and self-importance, providing support for the NVS validity.

\section{DISCUSSION OF THE ADJECTIVE MEASURES OF NARCISSISM}

Despite the fact that the NGS and the NVS were designed to measure grandiosity/agentic extraversion and vulnerability/neuroticism exclusively (Crowe et al., 2016, 2018), it seems that they also capture some elements of self-importance; however these elements different in nature between the NGS and the NVS. Weiss, Campbell, Lynam, and Miller (2019) argued that although antagonism is indeed the core trait of narcissism, which is in line with the NSM (Krizan \& Herlache, 2018), its role is different across grandiose and vulnerable narcissism. More specifically, the antagonistic traits vary across them with more internalized expressions (e.g., anger) being more typical for vulnerable narcissism and more externalized expressions (e.g., aggression) being prototypical for grandiose narcissism (Weiss et al., 2019). The NGS correlates strongly with indicators of the entitlement dimension such as the Psychological Entitlement Scale (Campbell, Bonacci, Shelton, Exline, \& Bushman, 2004), and also to a lesser extent with measures of vulnerable narcissism. In turn, whereas the NVS correlates weakly and negatively with most of the grandiosity measures, it is also positively associated with entitlement indicators such as narcissistic rivalry (Back et al., 2013). Indeed, both the NGS and NVS lists of adjectives, in addition to the dimension specific words (e.g., glorious and superior in the NGS and fragile and self-absorbed in the NVS), refer to antagonism (e.g., envied, dominant for the NGS and envy, irritable for the NVS). Wright and Edershile (2018) suggest that the NGS is a pure marker of grandiosity/ agentic extraversion. However, as there is not enough empirical evidence to claim this unambiguously, especially in regard to the role of antagonism in narcissism, further research is needed.

Interestingly, virtually all of the adjectives in the NGS refer to the agentic domain, such as prominent, brilliant, dominant, or powerful, while the adjectives in the NVS refer to the negatively valued agentic (e.g., ignored, misunderstood, insecure) and communal domains (e.g., resentful, envious), albeit this might be the result of referring to negative internal states. This demonstrates the dominance of the agentic conceptualization of narcissism in research (see Gebauer et al., 2012 for discussion). This default focus on agency in measuring grandiose narcissism is congruent with the observed dominance of agentic (over communal) content in maintaining high self-esteem (Wojciszke, Szymkow, \& Abele, 2008) and focus on agency among narcissistic individuals (Grijalva \& Zhang, 2016). However, as recent works on communal self-enhancement suggest, this could reflect either grandiose or vulnerable expressions (Gebauer \& Sedikides, 2018). Whilst the NGS measures only the agentic form of grandiose narcissism, the NVS includes both aspects, and therefore one could posit that mixing two the domains in one measure could lead to confusing and ambiguous results. 


\section{MULTIDIMENSIONAL MEASURES OF NARCISSISM}

\section{PATHOLOGICAL NARCISSISM INVENTORY (PNI; PINCUS ET AL., 2009)}

Theoretical foundations. The underlying assumption is that it is possible to distinguish between normal and pathological expressions of narcissism, both of which are distinct dimensions of personality (Pincus et al., 2009). Pincus argued that normal narcissism (or subclinical; Paulhus \&Williams, 2002), which is present in all individuals, refers to characteristics of narcissism such as achievement motivation, high self-esteem and well-being or low depression, whereas pathological narcissism is more associated with the clinical, as pathological regulatory deficits and antagonistic strategies to cope with ego-threatening situations (Pincus et al., 2009). Cain, Pincus, and Ansell (2008), in their review of clinical and social/personality psychology literature, argued that pathological expressions of narcissism disclose themselves in both grandiosity and vulnerability.

Construction. Pincus et al. (2009) noted that in clinical practice, pathological expressions of narcissism were typically assessed using semistructured diagnostic interviews or using multidimensional pathology inventories (e.g., MMPI), which made the diagnosis inefficient. Because the existing measures of narcissism (i.e., the NPI and the HSNS) did not comprehensively assess clinically meaningful facets of pathological narcissism, Pincus et al. (2009) developed and validated the Pathological Narcissism Inventory. On the basis of a thorough review of the literature (Cain et al., 2008) and in consultation with professionals working with narcissistic patients, 131 items were developed covering seven dimensions representing vulnerable (contingent self-esteem, devaluing of others and need for others, narcissistic social avoidance) and grandiose (exploitativeness, entitlement, grandiose fantasies, and self-sacrificing self-enhancement) expressions of pathological narcissism. The PNI also borrows items directly from the NPI. This original pool of items was initially reduced to 105 items through the authors' ratings. This pool was explored in a principal component analysis on a sample of college students $(N=796)$, which suggested that a seven-component solution is optimal. The item pool was then reduced to 50 items on the basis of their component loadings, item intercorrelations, and their contribution to reliability. The selected items converged with the expected theoretical dimensions, however to increase the fidelity of measurement, two items were removed, two revised, and four were added resulting in a final version comprising 52 -items. This 52-item measure was then used in a confirmatory factor analysis on an independent sample $(N=2,801)$, which confirmed the seven correlated-factor structure of the PNI (although 13 error covariances between similarly worded items were introduced in the measurement model). All of the scales were moderately intercorrelated (mean $r=.40$ ) and reliable in their measurement with estimates ranging from .78 to .93. A subsequent study by Wright, Lukowitsky, Pincus, and Conroy (2010) examined the higher order factor structure of the PNI and provided evidence that narcissistic grandiosity (PNI-G; loaded by exploitativeness, self-sacrificing self-enhancement, and grandiose fantasies) and vulnerability (PNI-V; loaded by contingent self-esteem, hiding the self, devaluing, and entitlement rage) can be meaningfully assessed using the PNI. Note, however, that grandiosity as assessed by the PNI does not contain the extraversion and surgency of other grandiose narcissism measures.

FIVE FACTOR NARCISSISM INVENTORY (FFNI; GLOVER, MILLER, LYNAM, CREGO, \& WIDIGER, 2012)

Theoretical foundation. The Five-Factor Model of narcissism was proposed on the basis and in correspondence with the Five-Factor Model of personality (FFM; Costa \& McCrae,

PINCUSET AL:

Pathological narcissism reflects maladaptive personality organizaztion, psychological needs, and regulatory mechanisms 
1995). More specifically, it draws its theoretical descriptions of the prototypical narcissistic traits from the respective facets of the FFM, which capture both - grandiose and vulnerable expressions of narcissism (Glover et al., 2012). Studies which have analyzed expert opinions and meta-analyses of empirical research on the relationship between narcissism and the FFM facets have demonstrated that many of them are associated, especially in regard to agreeableness, but also to extraversion and neuroticism (Lynam \& Widiger, 2001; Samuel \& Widiger, 2004, 2008; Widiger, Trull, Clarkin, Sanderson, \& Costa, 2002). Glover et al. (2012) summarized the existing evidence and proposed that narcissism, within the framework of the FFM, can be presented through the lens of 15 facets, which were labeled: reactive anger, shame, indifference, need for admiration (neuroticism), exhibitionism, thrill-seeking, authoritativeness (extraversion), grandiose fantasies (openness to experience), cynicism/distrust, manipulativeness, exploitativeness, entitlement, lack of empathy, arrogance (agreeableness), and acclaim-seeking (conscientiousness).

Construction. The initial item pool of the FFNI comprised 390 items (30 per scale), which represents narcissistic variants of each selected FFM facet, was administered to $N=333$ participants. Half of the data was used for item construction and the other for scale validation. On the basis of the strength of the correlation between each of the FFNI items to their respective personality facets and to the eight different narcissism measures, the 148-items with the highest estimates were selected for the final version of the measure. In addition to the full version, a short form comprising 60-items exists (Sherman et al., 2015). The distinguished scales apart from grandiose fantasies were convergent with respective FFM facets (lowest $r=.46$, range .46-.74). The FFNI scales were also correlated with other narcissism measures, revealing that vulnerable scales (i.e., shame, need for admiration, reactive anger, and cynicism/distrust) and grandiose scales (all remaining) correlated most strongly with other vulnerable and grandiose narcissism measures. In addition to the possibility of scoring composites of grandiose and vulnerable narcissism using the FFNI, Miller et al. (2016) conducted an exploratory factor analysis on the FFNI scales and revealed that they can be organized within three higher-order factors corresponding to the basic traits: 1) antagonism (comprising exploitativeness, lack of empathy, entitlement, arrogance, reactive anger, distrust, manipulativeness, and thrill seeking); 2) neuroticism (comprising shame, need for admiration and indifference -reversely scored); and 3) agentic extraversion (comprising acclaim seeking, authoritativeness, grandiose fantasies, and exhibitionism). In regard to other narcissism measures, neuroticism was predominately related to vulnerable narcissism, agentic extraversion was predominately related to grandiose narcissism, while antagonism was related to both grandiose and vulnerable narcissism measures. In regard to the basic traits, distinguished higher-order factors demonstrated the highest correlations as hypothesized, while in regard to self-esteem, a negative relation was found for neuroticism, null for antagonism, and a positive relation for agentic extraversion (Miller et al., 2016). Both scoring possibilities (i.e., distinguishing between grandiose vs vulnerable narcissism and distinguishing antagonism, neuroticism, and agentic extraversion) can be used separately or in conjunction one with another.

\section{NARCISSISTIC ADMIRATION AND RIVALRY QUESTIONNAIRE (NARQ; BACK ET AL., 2013)}

Theoretical foundations. The Narcissistic Admiration and Rivalry Concept (NARC; Back et al., 2013) is a theoretical process model of grandiose narcissism, which conceptualizes it as a two-dimensional construct encompassing two distinct but positively related dimensions, disentangling the bright and the dark side of narcissism: admiration, which leads to social status seeking using self-promotion; and rivalry, which is used to avoid social failures through the means of self-defense (Back et al., 2013; Back, 2018). It was developed as an 
answer to the difficulty of measuring narcissism using the classical NPI (Back et al., 2013; Raskin \& Terry, 1988). Within the NARC framework, the most basic goal of narcissism is to maintain a grandiose view of the self, which can be done using two strategies - agentic (admiration) or antagonistic (rivalry). Each strategy has distinct behavioral dynamics, explained by specific affective-motivational, cognitive, and behavioral facets. Namely, the underlying motivational goal of admiration is striving to be unique, fueled by grandiose fantasies, which - especially during the zero acquaintance (Back, Schmukle, \& Egloff, 2010) - might result in charming behaviors; whilst the underlying motivational goal of rivalry is striving for supremacy, supported by thoughts of devaluation of other people, which may result in hostile and aggressive behaviors. Thus, as a result, the social interaction outcome of admiration might be social potency, which boosts the ego and catalyzes grandiose fantasies, while the result of rivalry might be social conflict, which threatens the ego and catalyzes the devaluation of others.

Construction. The initial pool of items covering the theoretically defined admiration and rivalry and their corresponding facets was selected and/or optimized in multiple rounds by the authors of the scale (Back et al., 2013), which resulted in a pool of 30 items. These items were the subject of two separate exploratory factor analyses for admiration and rivalry. The non-redundant items with acceptable factor loadings were retained for the final 18item version of the NARQ. In a subsequent study using a large online sample $(N=953)$, the hierarchical structure was confirmed with a confirmatory factor analysis. The following studies demonstrated that admiration and rivalry scores are temporally stable, shared by outside perceivers, and have distinct nomological networks. There is also a 6-item version of this scale, which has been validated in communality and convenience samples and has good psychometric properties (Leckelt et al., 2018).

\section{DISCUSSION OF THE MULTIDIMENSIONAL MEASURES OF NARCISSISM}

All of the aforementioned measures are based on assumption that narcissistic personality has a complex nature. For example, the NARQ and the FFNI remove the single factor problem of the NPI. And, while this creates an opportunity to move field forward, it also creates another problem of making basic interpretation more difficult. The factors distinguished by the NARQ and the FFNI are, however, well aligned with basic personality traits (Miller et al., 2017; Rogoza, Wyszyńska, Maćkiewicz, \& Cieciuch, 2016) and thus, are worthy of exploration. All of the multidimensional narcissism measures explore slightly different aspects of grandiose and vulnerable narcissism. Despite the fact that, as compared to the classical methods, each one advances our understanding of narcissism, there are some controversies leading to exciting debates in the field of narcissism research. For instance: what is pathological narcissism? Is narcissistic rivalry a measure of vulnerable narcissism?

The NSM (Krizan \& Herlache, 2018; Krizan, 2018), which integrates existing theories of narcissism and elucidates the organization of narcissistic traits, seems to be a good theoretical platform to better understand the inconsistencies and controversies in the field. Within the NSM (Krizan \& Herlache, 2018), grandiosity and vulnerability are defined as distinct dimensions of narcissistic personality with a shared dimension of entitlement and egotism. These dimensions are organized within a semicircular structure. Namely, vulnerability and grandiosity are located almost at $90^{\circ}$, and the self-importance dimension is in-between them. The interpretation of this placement may be that while entitled features are shared in vulnerable and grandiose narcissism, some (i.e., those with an angular location exceeding $90^{\circ}$ ) vulnerable features might be negatively related to grandiose features. Krizan and Herlache (2018) argue that despite the common characteristics of entitlement and arrogance, grandiosity and vulnerability demonstrate distinct functional orientations

BACK ET AL:

Disentangling grandiose narcissism 
and nomological networks. For grandiosity, it is a high approach motivation resulting in an eager and hardy disposition, and for vulnerability it is a high avoidance motivation resulting in a stress-prone and volatile disposition. Among the implications introduced by the NSM, one of the more important is that grandiosity/vulnerability and grandiose/vulnerable narcissism are not interchangeable as the latter, in addition to elevated grandiosity/vulnerability, includes features of self-importance. We believe that there is a need to better empirically and theoretically understand the role of self-importance and other aspects of antagonism in grandiose and vulnerable narcissism, and that this may help us to better understand pathological narcissism.

Miller, Lynam, Hyatt, and Campbell (2017) argue that both grandiose and vulnerable narcissism can be considered as pathological, when their intensity is extreme and when there is clinically significant impairment. However, they disagree that normal and pathological narcissism are distinct dimensions, as the first originates from personality/social psychology and the latter from clinical psychology research (Pincus et al., 2009). Moreover, Miller, Lynam, and Campbell (2016) raise question about the validity of the PNI grandiosity (PNI-G) scale as it demonstrates weak correlations with scales typically associated with grandiose narcissism and it fails to match the expected nomological network of the NPD. Wright (2016) suggests that the PNI-G has different pattern of relations because it was designed as a broad measure of the maladaptive expressions of narcissism and it was not based on the narrowly defined NPD criteria (as the NPI originally was, Raskin \& Hall, 1979). While the PNI-G fails to follow the expert rating of the NPD, Wright (2016) notes that the exploitativeness scale does as well as the NPI or FFNI. Miller and colleagues (2016) note that this is solely because this scale was based on items directly taken from NPI. Wright (2016) finally agrees with Miller et al. (2016) that grandiosity is essential in understanding narcissism, however he is not convinced whether it may or may not be overt. On the other hand, Miller et al. (2016) agree that the PNI-G should not be discarded, because it captures a different aspect of grandiosity than the NPI or the FFNI (Wright et al.,2016).

In the terminology of the NSM (Krizan \& Herlache, 2018), it could be claimed that the NPI and the FFNI measure narcissistic grandiosity (with some elements of self-importance), while the PNI-G captures grandiose features which are closer to vulnerability (i.e., captures the self-importance dimension with some elements of grandiosity and vulnerability; Wright \& Edershile, 2018). This claim was not supported by an empirical analysis of the NSM structure (Krizan \& Herlache, 2018), as the PNI-G scales (excluding exploitativeness) loaded primarily on the vulnerability dimension (but their secondary loadings captured self-importance). However, it was supported by the work of Miller et al. (2016) as the PNI-G primarily correlates with agentic extraversion (representing NSM grandiosity), and secondarily with antagonism (NSM self-importance) and also, to small extent, with neuroticism (NSM vulnerability). Among all of grandiose and vulnerable narcissism scales, the PNI-G was the only one to positively correlate with all three dimensions (Miller et al., 2016). This last result corroborates the Pincus et al. (2009) claim that the PNI-G measures the pathological features of grandiosity, and the Miller et al. (2017) claim that vulnerable narcissism is characterized as pathological. Summarizing, the PNI-G diverges from typical measures of grandiosity (Miller et al., 2016; Wright, 2016) as, in the terms of the NSM (Krizan \& Herlache, 2018), it captures elements of entitlement as well as grandiosity and vulnerability; however, due to ambiguous empirical evidence (Krizan \& Herlache, 2018; Miller et al., 2016) more research investigating its location within the NSM is needed.

Is narcissistic rivalry a measure of vulnerable narcissism? Throughout their work, Miller and colleagues $(2014,2016)$ regard rivalry as a measure of vulnerable narcissism, while Back et al. (2013) explicitly state that the NARC and thus-rivalry-does not address vulnerable narcissism, although it was expected that rivalry would be more related to vulnerability. These discrepancies in theoretical perspectives cause confusion, which may be resolved by 
the NSM. Krizan and Herlache (2018) do not analyze the NARQ dimensions in structural terms, but they label rivalry as an indicator of entitlement and admiration as an indicator of grandiosity features of the spectrum. As self-importance is a shared narcissistic phenotype, positive associations with grandiosity and vulnerability are expected and observed (Back, 2018; Back et al., 2013; Krizan \& Herlache, 2018; Miller et al., 2016; Wright \& Edershile, 2018). Using the NSM to interpret the results reported in Miller et al. (2016) simplifies the interpretation, as rivalry correlates stronger $(r=.71)$ with antagonism than with vulnerability $(r=.27)$, as hypothesized. In addition to the differentiation of the bright (grandiosity) and blue (vulnerability) face of narcissism, including the dark (self-importance) face is also beneficial in the interpretation of the results (Rogoza, Żemojtel-Piotrowska, Kwiatkowska, \& Kwiatkowska, 2018). However, when expert ratings are analyzed, rivalry matches highly $(r=.84)$ with vulnerable narcissism (Miller et al., 2014) and when they are analyzed jointly, rivalry indeed demonstrates a slight skewness towards vulnerability (Rogoza et al., 2018).

Whereas the theoretical description of rivalry clearly represents antagonistic behaviors typical for grandiose narcissism (Back et al., 2013), the operationalization might actually represent, to some extent, behaviors typical for vulnerable narcissism. Within the NSM, the role of temperament is clearly outlined: Namely, that vulnerability represents an avoidant and grandiosity represents an approach motivation (Krizan \& Herlache, 2018). This distinction can be further linked to internalizing (vulnerability) and externalizing (grandiosity) pathology (Wright et al., 2012). Aggressiveness is the facet which is externalizing in nature, however in order to avoid floor effects Back et al. (2013) asked for mild aggressive reactions and internal precursors of aggressive behaviors (e.g., I often get annoyed when I am criticized), which in fact represents an internalization (Weiss et al., 2019). Because the experts did not compare rivalry to the self-importance dimension (Miller et al., 2014), its high correlation to vulnerable narcissism might be biased, particularly as aggressiveness represents items that are internalizing in nature. Therefore, further research on expert ratings and a possible revision of the aggressiveness facet are needed to address these problems.

\section{BEYOND NARCISSISM SPECTRUM MODEL}

\section{COMMUNAL NARCISSISM INVENTORY (GEBAUER ET AL., 2012)}

Theoretical background. The Communal Narcissism Inventory is grounded in the prominent Big Two concept of the duality of human functioning and perception (Bakan, 1966; Helgeson \& Fritz, 1999; Wojciszke \& Abele, 2008). According to Bakan (1966), agency is expressed through the mastery of the one's environment, the pursuit of individual goals, a focus on own achievements, power, competence, and self-assertion, while communion is related to a human focus on closeness to others, cooperation, and belonging (see Żemojtel-Piotrowska, Piotrowski, \& Clinton, 2017).

The agency-communion model is particularly important in the explanation of self-perception and self-esteem. For instance, Tafarodi and Swann (1995) indicated that the Rosenberg self-esteem scale (Rosenberg, 1965) refers to two distinct components: self-liking and self-respect. Typically, people enhance themselves in the agentic domain (Wojciszke et al., 2008), which is typical for the grandiosity dimension (Gebauer, Paulhus, \& Neberich, 2013; Rogoza, 2018). For this reason, grandiose narcissists enhance their intelligence, physical attractiveness, power skills or creativity, but do not enhance their morality, empathy, or friendliness (Campbell, Rudich, \& Sedikides, 2002; Gebauer et al., 2012; Gebauer, \& Sedikides, 2018). However, enhancing in the communal domain is also theoretically plausible. There 
GEBAUER ET AL:

Communal narcississm realizes its agentic goals in communal domain are people who present themselves as saints or super-heroes (Paulhus \& John, 1998), stressing their exceptional modesty, trustworthiness, and caring (Gebauer \& Sedikides, 2018). In addition, despite the fact that people tend to build their self-esteem on the basis of agency rather than communion, they are nevertheless interested in convincing others of their high morality and communion. This is related to the difference between self-profitable traits, like intelligence and others-profitable traits, like honesty (Peeters, 1992; Wojciszke et al., 2011). Therefore, individuals interested in maintaining satisfactory social relationships, are interested in presenting themselves as highly communal and therefore communal narcissism is not only plausible, but also could be socially profitable (Gebauer, \& Sedikides, 2018; Kwiatkowska, Jułkowski, Rogoza, Żemojtel-Piotrowska, \& Fatfouta, 2019).

Construction. The CNI was developed based on experimental material. Authors of the CNI invited participants to a laboratory where they asked about their thoughts and feelings related to their exceptional communal traits. As a result, two main kinds of expressions occurred: The first was related to exceptional community, like being the best friend one could imagine (the so called present-oriented factor), and the second, was based on grandiose fantasies about their exceptional role in world and being famous for exceptional deeds, such as solving world poverty (the so called future-oriented factor). The final version contains 16 items, eight per factor. However, a scale created in such a way will have a complex structure. The authors stressed its unidimensionality, however to obtain a reasonable model fit, they allowed for correlations between all items' errors (Gebauer et al., 2012). Żemojtel-Piotrowska et al. (2016) proposed a bi-factor structure to resolve the problems with the structure of the CNI, and confirmed its applicability in Polish and UK data, with scalar levels of measurement invariance across these countries.

Discussion. There is limited evidence supporting the distinctiveness of the two factors assumed by authors, i.e. the future-oriented and the present-oriented factors (Żemojtel-Piotrowska et al., 2016). Researchers typically report only a total general score. This measure of communal narcissism was based on the analysis of the grandiose self-thoughts reported by study participants. It has some advantages, as it is grounded in real-life, existing thoughts and feelings. However, some self-related thoughts could be accidentally omitted from the construct. For instance, the NPI includes aspects of self-enhancement in the agentic domain, such as the belief of exceptional agentic traits related to effectiveness, interpersonal skills related to possessing power, or physical attractiveness, but also aspects of overtly striving for power and a sense of entitlement. Therefore, the question arises, what is being measured by the CNI? It is just self-enhancement in a communal domain, or is it a more complex phenomenon, fully analogical to its agentic, NPI-based, counterpart? The answer is not easy, given the fact that communal narcissism is based on a specific form of self-presentation, in fact, an anti-narcissistic form. For instance, communal narcissists should demonstrate their modesty or exceptional prosocialness, despite the fact that they have the same narcissistic motives of self-importance, grandiosity, and dominance as their agentic counterparts. Therefore, overtly asking about entitlement or antagonistic aspects of narcissism is problematic due to communal self-presentation.

Wright et al. (2013) noted that one of the PNI vulnerable narcissism facets, namely, Self-Sacrificing Self-Enhancement (SSSE) refers to using altruistic acts to support one's inflated self-image (Pincus et al., 2009) and thus - among all of the PNI facets it might be separate from the rest of the scales due to its unique content. This raises the question of whether the CNI and SSSE are actually measuring distinct constructs? Rogoza and Fatfouta (2018) presented the first structural comparison of these two constructs, which showed negligible overlap in the structure between the scales. They both turned out to be related to the two conflicting (i.e., located on the opposite poles of a single dimension; Schwartz et al., 2012) motivational forces, specifically, self-enhancement and self-transcendence. However, neuroticism was distinctive as it positively correlated with the SSSE and was uncorrelated

Rogoza, R., Żemojtel-Piotrowska, M., Campbell, W. K. (2018). Measurement of narcissism: From classical applications to modern approaches. Studia Psychologica: Theoria et Praxis 1(18), 27—48. 
with the CNI. This led Rogoza and Fatfouta (2018) to label both constructs as communal narcissism, simultaneously emphasizing their distinctiveness by defining them as pathological and normal. These results are in line with Gebauer and Sedikides (2018), who demonstrated that pathological communal narcissism is generally related to worse, while normal communal narcissism is related to higher, psychological adjustment. Summarizing the distinctiveness of the two, Gebauer and Sedikides (2018) claimed that pathological communal narcissism reflects the communal expressions of vulnerable narcissism, while normal communal narcissism reflects the communal expressions of grandiose narcissism.

\section{COLLECTIVE NARCISSISM SCALE (GOLEC DE ZAVALA ET AL., 2009)}

Theoretical foundation. The idea of collective narcissism was developed in the field of social and political psychology. The term collective narcissism was used by Bizumic and Duckitt (2008), as a description of a special form of group-based self-importance, however it was focused mostly on ethnocentrism. Golec de Zavala et al. (2009) based their conception of collective narcissism on the classical understanding of grandiose narcissism, assuming that narcissism should be related to an inflated and unstable self-esteem (e.g., Emmons, 1987; Morf \& Rhodewalt, 2001; Raskin \& Terry, 1988). For this reason, during the validation of their concept, they searched for evidence supporting their hypothesis of insecure and unstable self-esteem and aggressive reactions following (group) ego-threats associated with group narcissism.

Collective narcissism was successfully introduced into social and political psychology. It became particularly important in predicting prejudice (Golec de Zavala et al., 2009; Golec de Zavala \& Cichocka, 2012; Golec de Zavala, Cichocka, \& Bilewicz, 2013), especially as a reaction to a threat to positive group image (Golec de Zavala et al., 2009, Golec de Zavala, Cichocka, \& Iskra-Golec, 2013) and conspiracy thinking, especially those related to a threat to in-group security (Cichocka, Golec de Zavala, Marchlewska, \& Olechowski, 2015; Cichocka, Marchlewska, \& Golec de Zavala, 2016). Cichocka (2017) stresses the role of insecure attachment underlying collective narcissism, contrary to high collective self-esteem, which is secure. Indeed, collective narcissism is positively associated to explicit self-esteem, and negatively related to implicit self-esteem (Golec de Zavala et al., 2009).

Measurement. The Collective Narcissism Scale (CNS, Golec de Zavala et al., 2009) is a 9-item scale developed on the basis of the NPI and the Millon Clinical Multiaxial Inventory-III (Millon, 2006). NPI items were transformed into group level items reflecting exceptionality, superiority, seeking for attention, sense of entitlement derived on the basis of the NPI, and supplemented by items reflecting sensitivity to criticism and a lack of recognition (see Golec de Zavala et al., 2009, p. 1077). As a result, the authors obtained a 23-item initial pool, which then was consulted on by experts from social, political, and clinical psychology, and with expertise in political science and conflict resolution. The initial validation sample was not too large, as it comprised 263 university students. The final version of the scale was reduced to 9 items. The authors of the CNS stressed its unidimensionality, and, similar to the authors of the CNI, they added correlations between five items to obtain reasonable model fit. Scale validation was conducted on Polish, US, and Mexican samples, which supported the cultural replicability of construct (Golec de Zavala et al., 2009).

Discussion. The CNS is a very specific scale among a broad family of narcissism measures. First of all, it was designed to explain phenomena typical for the social and political psychology fields. For this reason, the authors did not include personality psychology perspectives in the creation of the scale, and instead focused on the clinical understanding of narcissism (Golec de Zavala, 2018). Adding to this challenge is that the CNS lives in a different psychological space - political rather than an individual trait measures of narcissism.

GOLEC DE ZAVALA ET AL::

Collective narcissism is a form of in-group identification 
Further work is needed to integrate the CNS into the current trait models of narcissism, particularly because its status as a trait is still unclear.

\section{SUMMARY}

Within the previous sections we have introduced most important measures of grandiose and vulnerable narcissism and discussed them in the context of the NSM. To summarize our suggestions, Figure 1 presents how we visualize these scales to be jointly located within the multidimensional structure of narcissistic personality.

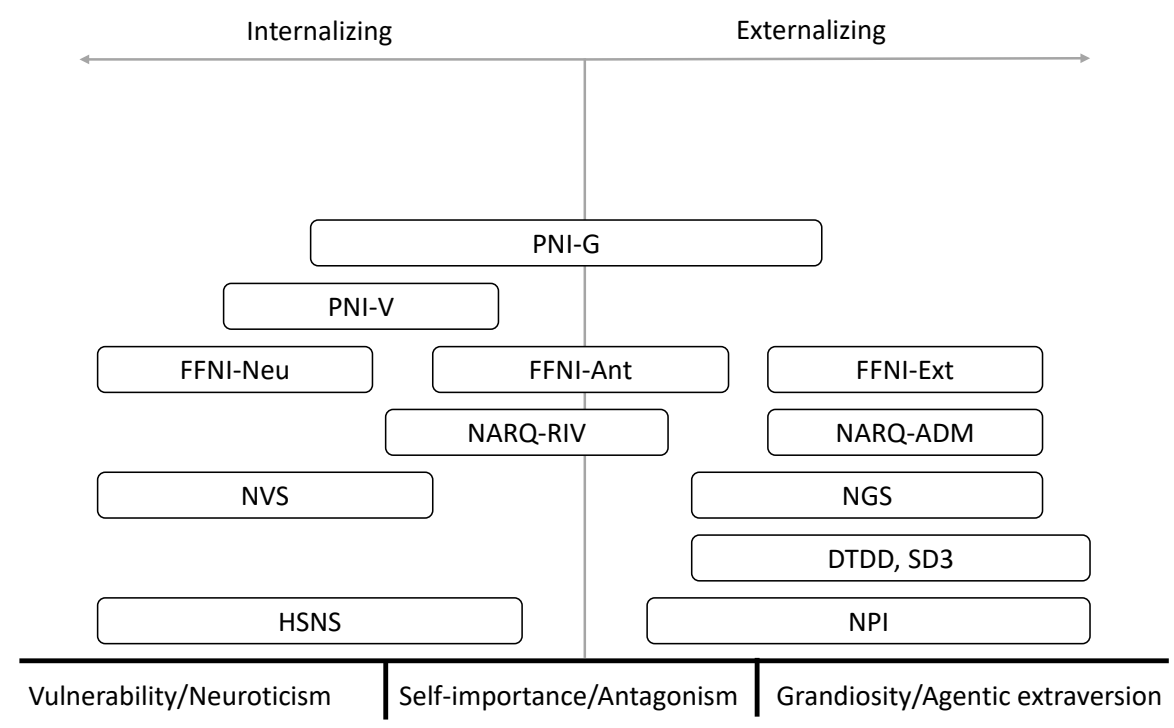

Figure 1. Different measures of narcissism within the multidimensional structure of narcissistic personality. Note. NPI = Narcissistic Personality Inventory; HSNS = Hypersensitive Narcissism Scale; DTDD = Dark Triad Dirty Dozen; SD3 = Short Dark Triad; NGS = Narcissistic Grandiosity Scale; NVS = Narcissistic Vulnerability Scale; NARQ = Narcissistic Admiration and Rivalry Questionnaire; ADM = Admiration; RIV = Rivalry; FFNI = Five Factor Narcissism Inventory; Ext = Extraversion; Ant $=$ Antagonism; Neu = Neuroticism; PNI = Pathological Narcissism Inventory; $\mathrm{V}=$ Vulnerability; $\mathrm{G}=$ Grandiosity. This figure is published under Creative Commons license 4.0 and is available at https://0sf.io/gtkbu/.

As Figure 1 shows, we agree that the central trait of narcissism is antagonism. However, as personality pathology can be divided into internalizing and externalizing (Wright et al., 2012) so can antagonism (Weiss et al., 2019), although little is known about these dynamics and future research is needed.It is important to note that the single peripheral dimension of narcissism (i.e., vulnerability/neuroticism or grandiosity/agentic extraversion) refers neither to vulnerable or to grandiose narcissism, because it is the central dimension of self-importance/antagonism, which defines narcissism (Krizan, 2018; Miller et al., 2017; Weiss et al., 2019; Wright \& Edershile, 2018). Thus, some of the existing one-dimensional measures might better capture some specific features of, for example, grandiosity/agentic extraversion (e.g., NPI, SD3) but they arguably lack satisfactory coverage of the antagonistic aspects of narcissism. If one wants to capture the entire range of antagonism, rather than simply the facets of antagonism that hang together with the more extraversion-saturated aspects of grandiose narcissism, a different or additional measure is needed. We encourage researchers to choose the measure which will be the best suited to realize their aims and goals. Below, 
we present some additional information, that may be useful during the measure selection process.

Narcissistic Personality Inventory - this measure could be used to assess primarily grandiosity/agentic extraversion with some elements of externalizing antagonism (Wright \& Edershile, 2018).

Hypersensitive Narcissism Inventory - the HSNS effectively measures vulnerability/neuroticism (Wright \& Edershile, 2018). As some studies have demonstrated, the HSNS also measures internalizing expressions of antagonism (e.g., Miller et al., 2014). When used in conjunction with the NPI it could potentially be used to assess narcissistic personalities, however they would not provide an opportunity to disentangle the antagonistic expressions of vulnerable and grandiose narcissism.

Dark Triad Dirty Dozen and Short Dark Triad - both of these measures were inspired by the NPI, and thus they are best able to assess primarily grandiosity/agentic extraversion dimension, with limited coverage of the externalizing expressions of antagonism.

Single Item Narcissism Scale - the existing empirical evidence does not allow us to make any conclusions, however the SINS was designed as a measure of grandiosity, but it may capture vulnerability and antagonism as well. Thus, although we cannot recommend it as a primary measure, it might be useful as a screening tool, however future research is needed.

Narcissistic Grandiosity and Vulnerability Scales - both measures are good examples of short and easy to administer scales, which is advantageous in studies requiring such tools (e.g., in EMA). Although, both scales comprise some limited elements of antagonism (externalizing and internalizing respectively), they predominately assess their respective dimensions (Wright \& Edershile, 2018). They may be used as replacements for the NPI and the HSNS.

Pathological Narcissism Inventory - whilst the labels of these scales may suggest that the PNI effectively measures vulnerability and grandiosity (Pincus et al., 2009), empirical evidence demonstrates that best captures the self-importance dimension of narcissism and vulnerability. More specifically, the PNI-V captures mostly narcissistic vulnerability with some elements of self-importance, while the PNI-G captures mostly self-importance with some elements of both, vulnerability and grandiosity (Wright \& Edershile, 2018).

Five Factor Narcissism Inventory - is the first scale which effectively assesses a three-factor model of narcissism as well as grandiose vs. vulnerable (Krizan \& Herlache, 2018; Miller et al., 2017; Wright \& Edershile, 2018). Thus, using the FFNI offers more precision than the NPI or the HSNS. The FFNI is derived directly from the Five Factor Trait model, so it has theoretical roots in trait theory and structural models of personality. This can be a limitation or a strength depending on the researcher's interest.

Narcissistic Admiration and Rivalry Questionnaire - it was the first measure to disentangle the more self-promoting from the more antagonistic aspects of narcissism (Back et al., 2013). In addition, it captures vulnerability to a limited extent (Wright \& Edershile, 2018). The main advantage of the NARQ is the underlying theoretical model - the NARC: The NARC dimensions can be seen either dimensionally or as a part of the process model of grandiose narcissism.

Communal Narcissism Inventory - this is currently the only measure of communal narcissism. Thus, it is recommended for research on communal narcissism, however future research might develop and propose a refined and more theoretically advanced measure.

Collective Narcissism Scale - similar to the CNI, it is also the only available measure of collective narcissism. Although it was designed on the basis of grandiose narcissism, it tends to capture more vulnerable expressions (Golec de Zavala, 2018), which emphasizes the difficulties in explaining the role of collective narcissism within narcissistic personalities. Thus, future theoretical and empirical work is needed to clearly locate collective narcissism in respect to all other narcissistic traits. 


\section{CONCLUSIONS}

We now have a much more solid understanding of the measure of narcissism than we did a decade ago. There is currently wide agreement that there are two basic forms of narcissism, grandiose and vulnerable, and that good stand-alone measures exist for each. Researchers can opt for those - for example, they can use a short form of the NPI and the HNSN in a study - or they can use measures that include both, like the FFNI, or somewhat more nuanced versions of the two, like the NARQ or PNI. We hope this overview has given you some ideas about the varied benefits and trade-offs of the various measures.

Narcissism is a heterogenous construct with many different measures. The existing knowledge is extensive, allowing us to develop sophisticated theoretical models (Krizan \& Heralche, 2018) which lead to an improved understanding of the functioning of narcissistic individuals. Simultaneously, in the other areas (e.g., in research on communal and collective narcissism), the knowledge and empirical evidence is limited and underrepresented. However, the ongoing research provides new insights each day and the studies devoted to the understanding of narcissism are constantly moving forward.

\section{ACKN O W LEDGEMENTS}

The authors have no conflict of interest to declare. The work of Radostaw Rogoza was supported by grant 2015/19/N/HS6/00685 from the National Science Centre, Poland. The work of Magdalena Żemojtel-Piotrowska was supported by grant 2017/26/E/HS6/00282 from the National Science Centre, Poland.

\section{REFERENCES}

Abele, A., \& Wojciszke, B. (2007). Agency and communion from the perspective of self and others. Journal of Personality and Social Psychology, 93, 751-763. doi:10.1037/0022-3514.93.5.751

Abele, A.E., Hauke, N., Peters, K., Louvet, E., Szymkow, A., \& Duan, Y. (2016). Facets of the fundamental content dimensions: Agency with competence and assertiveness-communion with warmth and morality. Frontiers in Psychology, 7, 1810. doi:10.3389/fpsyg.2016.01810

Ackerman, R.A., Donnellan, M.B., Roberts, B.W., \& Fraley, R.C. (2016). The effect of response format on the psychometric properties of the Narcissistic Personality Inventory: Consequences for item meaning and factor structure. Assessment, 23, 203-220. doi:10.1177/1073191114568113

Ackerman, R.A., Witt, E.A., Donnellan, M.B., Trzesniewski, K.H., Robins, R.W., \& Kashy, D.A. (2011). What does the narcissistic personality inventory really measure? Assessment, 18,67-87. doi:10.1177/1073191110382845

American Psychiatric Association - APA. (1980). Diagnostic and statistical manual of mental disorders: DSM-III. Washington, DC: APA.

Ames, D.R., Rose, P., \& Anderson, C.P. (2006). The NPI-16 as a short measure of narcissism. Journal of Research in Personality, 40, 440-450. doi:10.1016/j. jrp.2005.03.002

Arble, E.P. (2006). Evaluating the psychometric properties of the hypersensitive narcissism scale: Implications for the distinction of covert and overt narcissism. Master's thesis, Eastern Michigan University. 
Ashby, H. U., Lee, R. R., \& Duke, E. H. (1979). A narcissistic personality disorder MMPI scale. Paper presented at the 87th annual meeting of the American Psychological Association, New York, NY.

Back, M.D. (2018). The narcissistic admiration and rivalry concept. In A.D. Hermann, A.B. Brunnel, \& J.D. Foster (Eds.), Handbook of trait narcissism. Key advances, research methods, and controversies (pp. 57-67). Cham: Springer. doi:10.1007/978-3-319-92171-6_6

Back, M.D., Küfner, A.C.P., Dufner, M., Gerlach, T.M., Rauthmann, J.F., \& Denissen, J.J.A. (2013). Narcissistic admiration and rivalry: disentangling the bright and dark sides of narcissism. Journal of Personality and Social Psychology, 105, 1013-1037. doi:10.1037/a0034431

Back, M.D., Schmukle, S.C., \& Egloff, B. (2010). Why are narcissists so charming at the first sight? Decoding the narcissism-popularity link at zero acquaintance. Journal of Personality and Social Psychology, 98, 132-145. doi:10.1037/a0016338

Bakan, D. (1966). The duality of human existence. Reading, PA: Addison-Wesley.

Barelds, D.P.H., \& Dijkstra, P. (2010). Narcissistic Personality Inventory: Structure of the adapted Dutch version. Scandinavian Journal of Psychology, 51, 132-138. doi:10.1111/j.1467-9450.2009.00737.x

Benet-Martinez, V., \& John, O.P. (1998). Los Cinco Grandes across cultures and ethnic groups: Multitrait-multimethod matrix analyses of the Big Five in Spanish and English. Journal of Personality and Social Psychology, 75, 729-750. doi:10.1037/0022-3514.75.3.729

Bizumic, B., \& Duckitt, J. (2008) "My group is not worthy of me": Narcissism and ethnocentrism. Political Psychology, 29, 437-453. doi:10.1111/ j.1467-9221.2008.00638.x

Brown, R.P., Budzek, K., \& Tamborski, M. (2009). On the meaning and measure of narcissism. Personality and Social Psychology Bulletin, 35, 951-964. doi:10.1177/0146167209335461

Cain, N. M., Pincus, A. L., \& Ansell, E. B. (2008). Narcissism at the crossroads: Phenotypic description of pathological narcissism across clinical theory, social/personality psychology, and psychiatric diagnosis. Clinical Psychology Review, 28, 638-656. doi:10.1016/j.cpr.2007.09.006

Cichocka, A. (2017). Understanding defensive and secure in-group positivity: The role of collective narcissism. European Review of Social Psychology, 27, 283-317. doi:10.1080/10463283.2016.1252530

Cichocka, A., Marchlewska, M., \& Golec de Zavala, A. (2016). Does self-love or self-hate predict conspiracy beliefs? Narcissism, self-esteem, and the endorsement of conspiracy theories. Social Psychological and Personality Science, 7, 157-166. doi:10.1177/1948550615616170

Cichocka, A., Marchlewska, M., Golec de Zavala, A., \& Olechowski, M. (2016). 'They will not control us': Ingroup positivity and belief in intergroup conspiracies. British Journal of Psychology, 107, 556-576. doi:10.1111/bjop.12158

Corry, N., Merrit, R.D., Mrug, S., \& Pamp, B. (2008). The factor structure of the Narcissistic Personality Inventory. Journal of Personality Assessment, 90 , 593-600. doi:10.1080/00223890802388590

Costa, P.T., \& McCrae, R.R. (1995). Domains and factors: Hierarchical personality assessment using the NEO personality inventory. Journal of Personality Assessment, 64, 21-50. doi:10.1207/s15327752jpa6401_2

Crowe, M.L., Carter, N.T., Campbell, W.K., \& Miller, J.D. (2016). Validation of the Narcissistic Grandiosity Scale and creation of reduced item variants. Psychological Assessment, 28, 1550-1560. doi:10.1037/pas0000281

Crowe, M.L., Edershile, E.A., Wright, A.G.C., Campbell, W.K., Lynam, D.R., \& Miller, J.D. (2018). Development and validation of the Narcissistic Vulnerability Scale: An adjective rating scale. Psychological Assessment, 30, 978-983. doi:10.1037/pas0000578

Emmons, R.A. (1984). Factor analysis and construct validity of the Narcissistic Personality Inventory. Journal of Personality Assessment, 48, 291-300. doi:10.1207/s15327752jpa4803_11

Emmons, R.A. (1987). Narcissism: Theory and measurement. Journal of Personality and Social Psychology, 52, 11-17. doi:10.1037/0022-3514.52.1.11

Fossatti, A., Borroni, S., Grazioli, F., Dornetti, L., Marcassoli, I., Maffei, C., \& Cheek, J. (2009). Tracking the hypersensitive dimension in narcissism: Reliability and validity of the Hypersensitive Narcissism Scale. Personality and Mental Health, 3, 235-247. doi:10.1002/pmh.92

Furnham, A., Richards, S.C., \& Paulhus, D.L. (2013). The Dark Triad of personality: A 10-year review. Social and Personality Compass, 7, 199-216. doi:10.1111/spc3.12018

Campbell, W.K.C., Rudich, E.A., \& Sedikides, C. (2002). Narcissism, self-esteem, and the positivity of self-views: Two portraits of self-love. Personality and Social Psychology Bulletin, 28, 358-368. doi:10.1177/0146167202286007

Gebauer, J., \& Sedikides, C. (2018). Communal narcissism: theoretical and empirical support (pp.69-78). In: A.D. Herman, A.B. Brunel \& J.D. Foster (Eds.), Handbook of trait narcissism. Key advances, research methods, and controversies. Cham: Springer. doi:10.1007/978-3-319-92171-6

Gebauer, J.E., Paulhus, D.L., \& Neberich, W. (2013). Big Two personality and religiosity across cultures: Communals as religious conformists and agentics as religious contrarians. Social Psychological and Personality Science, 4, 21-30. doi:10.1177/1948550612442553

Gebauer, J.E., Sedikides, C., Verplanken, B., \& Maio, G.R. (2012). Communal narcissism. Journal of Personality and Social Psychology, 103, 854-878. doi:10.1037/a0029629

Gentile, B., Miller, J. D., Hoffman, B. J., Reidy, D. E., Zeichner, A., \& Campbell, W. K. (2013). A test of two brief measures of grandiose narcissism: The Narcissistic Personality Inventory-13 and the Narcissistic Personality Inventory-16. Psychological Assessment, 25, 1120-1136. doi:10.1037/ a0033192

Glover, N., Miller, J.D., Lynam, D.R., Crego, C., \& Widiger, T.A. (2012). The Five-Factor Narcissism Inventory: A five factor measure of narcissistic personality traits. Journal of Personality Assessment, 94, 500-512. doi:10.1080/00223891.2012.670680

Golec de Zavala, A. (2018). Collective narcissism (pp.79-88). In: A.D. Herman, A.B. Brunel \& J.D. Foster (Eds.), Handbook oftrait narcissism. Key advances, research methods, and controversies (pp. 79-88). Cham: Springer. doi:10.1007/978-3-319-92171-6_8 
Golec de Zavala, A., \& Cichocka, A. (2012). Collective narcissism and anti-Semitism in Poland: the mediating role of siege beliefs and the conspiracy stereotype of Jews. Group Processes \& Intergroup Relations, 15, 213-229. doi:10.1177/1368430211420891

Golec de Zavala, A., Cichocka, A., \& Bilewicz, M. (2013). The paradox of in-group love: Narcissistic and genuine positive group regard have reverse effects on out-group attitudes. Journal of Personality, 81, 16-28. doi:10.1111/j.1467-6494.2012.00779.x

Golec de Zavala, A., Cichocka, A., \& Iskra-Golec, I. (2013). Collective narcissism moderates the effect of in-group image threat on outgroup hostility. Journal of Personality and Social Psychology, 104, 1019-1039. doi:10.1037/a0032215

Golec de Zavala, A., Cichocka, A., Eidelson, R., \& Jayawickreme, N. (2009). Collective narcissism and its social consequences. Journal of Personality and Social Psychology, 97, 1074-1096. doi:10.1037/a0016904

Grijalva, E., \& Zhang, L. (2016). A review and meta-analysis of narcissists' self-enhancement tendencies. Personality and Social Psychology Bulletin, 42, 3-24. doi:10.1177/0146167215611636

Helgeson, V.S., \& Fritz, H.L. (1999). Unmitigated agency and unmitigated communion: Distinctions from agency and communion. Journal of Research in Personality, 33, 131-158. doi:10.1006/jrpe.1999.2241

Hendin, H.M., \& Cheek, J.M. (1997). Assessing hypersensitive narcissism: A reexamination of Murray's Narcism Scale. Journal of Research in Personality, 31, 588-599. doi:10.1006/jrpe.1997.2204

John, O.P., Donahue, E.M., \& Kentle, R.L. (1991). The Big Five Inventory: Versions 4a and 54. Technical report. Institute of Personality and Social Research, University of California, Berkeley, CA.

Jonason, P.K., \& Webster, G.D. (2010). The dirty dozen: a concise measure of the dark triad. Psychological assessment, 22, 420-432. doi:10.1037/ a0019265

Jones, D.N., \& Paulhus, D.L. (2011). The role of impulsivity in the Dark Triad of personality. Personality and Individual Differences, 51, 679-682. doi:10.1016/j.paid.2011.04.011

Jones, D.N., \& Paulhus, D.L. (2014). Introducing the Short Dark Triad (SD3): A brief measure of dark personality traits. Assessment, 21, 28-41. doi:10.1177/1073191113514105

Kansi, J., (2003). The Narcissistic Personality Inventory: applicability in a Swedish population sample. Scandinavian Journal of Psychology, 44, 441-448. doi:10.1046/j.1467-9450.2003.00365.x

Konrath, S., Meier, B.P., \& Bushman, B.J. (2014). Development and validation of the Single Item Narcissism Scale (SINS). PLoS One, 9, e103469. doi:10.1371/journal.pone.0103469

Krizan, Z. (2018). The Narcissism Spectrum Model: A spectrum perspective on narcissistic personality. In A.D. Hermann, A.B. Brunnel, \& J.D. Foster (Eds.), Handbook of trait narcissism. Key advances, research methods, and controversies (pp. 15-25). Cham: Springer. doi:10.1007/978-3-319-921716_2

Krizan, Z., \& Herlache, A.D. (2018). The Narcissism Spectrum Model: A synthetic view of narcissistic personality. Personality and Social Psychology Review, 22, 3-31. doi:10.1177/1088868316685018

Kwiatkowska, M.M., Jułkowski, T., Rogoza, R., Żemojtel-Piotrowska, M.A., \& Fatfouta, R. (2019). Narcissism and trust: Differential impact of agentic, antagonistic, and communal narcissism. Personality and Individual Differences, 137, 139-143. doi:10.1016/j.paid.2018.08.027

Leckelt, M., Wetzel, E., Gerlach, T.M., Ackerman, R.A., Miller, J.D., Chopik, W.J., Penke, L., Geukes, K., Küfner, A.C.P., Hutteman, R., Richter, D., Renner, K.H., Allroggen, M., Brechen, C., Campbell, W.K., Grossman, I., \& Back, M.D. (2018). Validation of the Narcissistic Admiration and Rivalry Questionnaire short scale (NARQ-S) in convenience and representative samples. Psychological Assessment, 30, 86-96. doi:10.1037/pas0000433

Lynam, D.R., \& Widiger, T.A. (2001). Using the five-factor model to represent the DSM-IV personality disorders: An expert consensus approach. Journal of Abnormal Psychology, 110, 401-412. doi:10.1037/0021-843X.110.3.401

Miller, J.D., \& Campbell, W.K. (2008). Comparing clinical and social-personality conceptualizations of narcissism. Journal of Personality, 76, 449-476. doi:10.1111/j.1467-6494.2008.00492.x

Miller, J. D., Gentile, B., Carter, N. T., Crowe, M., Hoffman, B. J., \& Campbell, W. K. (2018). A comparison of the nomological networks associated with forced-choice and Likert formats of the Narcissistic Personality Inventory. Journal of personality assessment, 100, 259-267. doi:10.1080/00 223891.2017.1310731

Miller, J.D., Lynam, D.R., \& Campbell, W.K. (2016). Rejoinder: A construct validity approach to the assessment of narcissism. Assessment, 23, 18-22. doi:10.1177/1073191115608943

Miller, J.D., Lynam, D.R., Hyatt, C.S., \& Campbell, W.K. (2017). Controversies in narcissism. Annual Revie w of Clinical Psychology, 13, 1.1-1.25. doi:10.1146/annurev-clinpsy-032816-045244

Miller, J.D., Lynam, D.R., McCain, J.L., Few, L.R., Crego, C., Widiger, T.A., \& Campbell, W.K. (2015). Thinking structurally about narcissism: An examination of the Five-Factor Narcissism Inventory and its components. Journal of Personality Disorders, 29, 1-18. doi:10.1521/pedi_2015_29_177

Miller, J.D., McCain, J., Lynam, D.R., Few, L.R., Gentile, B., MacKillop, J., \& Campbell, W.K. (2014). A comparison of the criterion validity of popular measures of narcissism and narcissistic personality disorder via the use of expert ratings. Psychological Assessment, 26, 958-969. doi:10.1037/ a0036613.2012.685907

Miller, J.D., Price, J., \& Campbell, W.K. (2012). Is the Narcissistic Personality Inventory still relevant? A test of independent grandiosity and entitlement scales in the assessment of narcissism. Assessment, 19, 8-13. doi:10.1177/1073191111429390

Millon, T. (2006). Millon Clinical Multiaxial Inventory—III (MCMI-III) manual (3rd ed.). Minneapolis, MN: Pearson Assessments.

Morf, C.C., \& Rhodewalt, F. (2001). Unraveling the paradoxes of narcissism: A dynamic self-regulatory processing model. Psychological Inquiry, 12, 177-196. doi:10.1207/S15327965PLI1204_1 
Murray, H.A. (1938). Explorations in personality. New York: Oxford University Press.

Paulhus, D.L. (2014). Toward a taxonomy of dark personalities. Current Directions in Psychological Science, 23, 421-426. doi:10.1177/0963721414547737

Paulhus, D.L., \& John, O.P. (1998). Egoistic and moralistic bias in self-perceptions: The interplay of self-deceptive styles with basic traits and motives. Journal of Personality, 66, 1025-1060. doi:10.1111/1467-6494.00041

Paulhus, D.L., \& Williams, K.M. (2002). The Dark Triad of personality: Narcissism, Machiavellianism, and psychopathy. Journal of Research in Personality, 36, 556-563. doi:10.1016/50092-6566(02)00505-6

Pincus, A.L., Ansell, E.B., Pimentel, C.A., Cain, N.M., Wright, A.G.C., \& Levy, K.N. (2009). Initial construction and validation of the Pathological Narcissism Inventory. Psychological Assessment, 21, 365-379. doi:10.1037/a0016530

Podsakoff, P.M., MacKenzie, S.B., \& Podsakoff, N.P. (2012). Sources of method bias in social science research and recommendations on how to control it. Annual Review of Psychology, 63, 539-569. doi:10.1146/annurev-psych-120710-100452

Raskin, R., \& Hall, C. S. (1979). The Narcissistic Personality Inventory. Psychological Reports, 45, 590. doi:10.2466/pr0.1979.45.2.590

Raskin, R., \& Hall, C.S. (1981). The Narcissistic Personality Inventory: Alternate form reliability and further evidence of construct validity. Journal of Personality and Social Psychology, 45, 159-162. doi:10.1207/s15327752jpa4502_10

Raskin, R., \& Terry, H. (1988). A principal-components analysis of the Narcissistic Personality Inventory and further evidence of its construct validity. Journal of Personality and Social Psychology, 54, 890-902. doi:10.1037/0022-3514.54.5.890

Rogoza, R. (2018). Narcissist unmasked. Looking for the narcissistic decision-making mechanism: A contribution from the Big Five. Social Psychological Bulletin, 13, e26623. doi:10.5964/spb.v13i2.26623

Rogoza, R., \& Cieciuch, J. (2018). Dark Triad traits and their structure: An empirical approach. Current Psychology. doi:10.1007/s12144-018-9834-6

Rogoza, R., \& Fatfouta, R. (2018). When helping others goes wrong: Normal and pathological communal narcissism in their relation to personality traits and basic values. Personality and Individual Differences. Advance online publication. doi:10.1016/j.paid.2018.03.039

Rogoza, R., Kowalski, C.M., Schermer, J.A. (2019). The Dark Triad traits within the framework of the Circumplex Model of Personality Metatraits. Journal of Individual Differences. doi: 10.1027/1614-0001/a000289

Rogoza, R., Wyszyńska, P., Maćkiewicz, M., Cieciuch, J. (2016). Differentiation of the two narcissistic faces in their relations to personality traits and basic values. Personality and Individual Differences, 95, 85-88. doi: 10.1016/j.paid.2016.02.038

Rogoza, R., Żemojtel-Piotrowska, M., Kwiatkowska, M.M., \& Kwiatkowska, K. (2018). The bright, the dark, and the blue face of narcissism: The spectrum of narcissism in its relations to the metatraits of personality, self-esteem, and nomological network of shyness, loneliness and empathy. Frontiers in Psychology, 9, 343. doi:10.3389/fpsyg.2018.00343

Rosenberg, M. (1965). Society and the adolescent self-image. Princeton, NJ: Princeton University Press.

Rosenthal, S. A., Hooley, J. M., Montoya, R. M., van der Linden, S. L., \& Steshenko, Y. (2019). The Narcissistic Grandiosity Scale: A measure to distinguish narcissistic grandiosity from high self-esteem. Assessment. Advance online publication. doi:10.1177/1073191119858410

Samuel, D. B., \& Widiger, T. A. (2004). Clinicians' personality descriptions of prototypic personality disorders. Journal of Personality Disorders, 18, 286308. doi:10.1521/pedi.18.3.286.35446

Samuel, D.B., \& Widiger, T.A. (2008). Convergence of narcissism measures from the perspective of general personality functioning. Assessment, 15, 364-374. doi:10.1177/1073191108314278

Sherman, E.D., Miller, J.D., Few, L.R., Campbell, W.K., Widiger, T.A., Crego, C., \& Lynam, D.R. (2015). Development of a short form of the Five Factor Narcissism Inventory. Psychological Assessment, 27, 1110-1106. doi:10.1037/pas0000100

Serkownek, K. (1975). Subscales for scales 5 and 0 of the MMPI. Unpublished manuscript.

Svindseth, M.F., Sorebo, 0., Nottestad, J.A., Roaldset, J.0., Wallin, J., \& Dahl, A.A. (2009). Psychometric examination and normative data for the Narcissistic Personality Inventory 29 item version. Scandinavian Journal of Psychology, 50, 151-159. doi:10.1111/j.1467-9450.2008.00686.X

Tafarodi, R.W., \& Swann, W.B. (1995). Self-liking and self-competence as dimensions of global self-esteem: Initial validation of a measure. Journal of Personality Assessment 65, 322-342. doi:10.1207/s15327752jpa6502_8

Van den Linden, S. \& Rosenthal, S. (2016). Measuring narcissism with a single question? A replication and extension of the Single-Item Narcissism Scale (SINS). Personality and Individual Differences. doi:10.1016/j.paid.2015.10.050

Weiss, B., Campbell, W.K., Lynam, D.R., Miller, J.D. (2019). A trifurcated model of narcissism: On the pivotal role of trait antagonism. In J. Miller \& D. Lynam (Eds.), The handbook of antagonism. Cambridge: Academic Press.

Widiger, T.A., Trull, T.J., Clarkin, J.F., Sanderson, C., \& Costa, P.T., Jr. (2002). A description of the DSM-IV personality disorders with the five-factor model of personality. In P. T. Costa, Jr. \& T. A. Widiger (Eds.), Personality disorders and the five-factor model of personality (pp. 89-99). Washington, DC, US: American Psychological Association. doi:10.1037/10423-006

Wink, P. (1991). Two faces of narcissism. Personality and Individual Differences, 61, 590-597. doi:10.1037/0022-3514.61.4.590

Wojciszke, B., Baryla, W., Parzuchowski, M., Szymkow, A., \& Abele, A.E. (2011). Self-esteem is dominated by agentic over communal information. European Journal of Social Psychology, 41, 617-627. doi:10.1002/ejsp.791

Wright, A.G.C. (2016). On the measure and mismeasure of narcissism: A response to "Measures of narcissism and their relations to DSM-5 pathological traits: A critical reappraisal". Assessment, 23, 10-17. doi:10.1177/1073191115599054

Wright, A.G.C., \& Edershile, E. (2018). Issues resolved and unresolved in pathological narcissism. Current Opinion in Psychology, 21, 74-79. doi:10.1016/j.copsyc.2017.10.001 
Wright, A.G.C., Lukowitsky, M.R., Pincus, A.L., \& Conroy, D.E. (2010). The higher order factor structure and gender invariance of the Pathological Narcissism Inventory. Assessment, 17, 467-483. doi:10.1177/1073191110373227

Wright, A.G.C., Pincus, A.L., Thomas, K.M., Hopwood, C.J., Markon, K.E., \& Krueger, R.F. (2013). Conceptions of narcissism and the DSM-5 pathological personality traits. Assessment, 20, 339-352. doi:10.1177/1073191113486692

Wright, A.G.C., Thomas, K.M., Hopwood, C.J., Markon, K.E., Pincus, A.L., \& Krueger, R.F. (2012). The hierarchical structure of DSM-5 pathological personality traits. Journal of Abnormal Psychology, 121, 951-957. doi:10.1037/a0027669

Żemojtel-Piotrowska, M., Clinton, A., \& Piotrowski, J. (2014). Agentic and communal narcissism and subjective well-being: Are narcissistic individuals unhappy? A research report. Current /ssues in Personality Psychology, 2, 10-16. doi:10.5114/cipp.2014.43097

Żemojtel-Piotrowska, M., Czarna, A. Z., Piotrowski, J., Baran, T., \& Maltby, J. (2016). Structural validity of the Communal Narcissism Inventory (CNI): The bifactor model. Personality and Individual Differences, 90, 315-320. doi:10.1016/j.paid.2015.11.036

Żemojtel-Piotrowska, M., Piotrowski, J., Rogoza, R., Hitokoto, H., Baran, T., Maltby, J. (2018). Cross-cultural invariance of NPI-13: Entitlement as culturally specific, leadership and grandiosity as culturally universal. International Journal of Psychology. Advance online publication. doi:10.1002/ijop.12487 